PAPER

\title{
Long term experience of gamma knife radiosurgery for benign skull base meningiomas
}

\author{
W Kreil, J Luggin, I Fuchs, V Weigl, S Eustacchio, G Papaefthymiou
}

J Neurol Neurosurg Psychiatry 2005;76:1425-1430. doi: 10.1136/jnnp.2004.049213

See end of article for authors' affiliations

\section{Correspondence to:}

Dr W Kreil, Department of

Neurosurgery, Medical

University Graz,

Auenbruggerplatz 29

A-8036 Graz, Austria;

wolfgang.kreil@meduni-

graz.at

Received 5 July 2004

In revised form

12 December 2004

Accepted 8 February 2005

\begin{abstract}
Objectives: As most reports on the gamma knife have related only to short or mid-term results, we decided to evaluate the effectiveness and toxicity of radiosurgical treatment for benign skull base meningiomas in 200 patients with a follow up of 5-12 years to define the role of gamma knife radiosurgery (GKRS) for basal meningiomas and to provide further data for comparison with other treatment options.

Methods: In total, 99 patients were treated with a combination of microsurgical resection and GKRS. In 101 patients, GKRS was performed as the sole treatment option. Tumour volumes ranged from 0.38 to $89.8 \mathrm{~cm}^{3}$ (median $6.5 \mathrm{~cm}^{3}$ ), and doses of 7-25 Gy (median $12 \mathrm{~Gy}$ ) were given to the tumour borders at covering isodose volume curves (range $20-80 \%$, median $45 \%$ ).

Results: The actuarial progression free survival rate was $98.5 \%$ at 5 years and $97.2 \%$ at 10 years. Passing radiation induced oedema occurred in two patients (1\%). The neurological status improved in 83 cases $(41.5 \%)$, remained unaltered in $108(54 \%)$, and deteriorated in $9(4.5 \%)$. Worsening was transient in seven patients $(3.5 \%)$ and unrelated to tumour or treatment in one $(0.5 \%)$. Repeated microsurgical resection was performed in five patients following GKRS (2.5\%).

Conclusions: GKRS has proved to be an effective alternative to microsurgical resection, radiotherapy, and Linac based radiosurgery for adjunctive and primary treatment of selected patients with basal meningiomas. Because of the excellent long term tumour control rate and low morbidity associated with GKRS, this treatment option should be used more frequently in the therapeutic management of benign skull base meningiomas.
\end{abstract}

A dvances in diagnostic and interventional radiology, improved microsurgical techniques, interdisciplinary skull base teamwork, and developments in anaesthesia and postoperative intensive care have expanded the scope and safety of the surgical treatment of basal meningiomas. ${ }^{1}$ However, microsurgical resection of these tumours is frequently associated with considerable aggravation or new onset of neurological impairment, ${ }^{1-12}$ and meningioma recurrences are observed even when complete removal has been accomplished. ${ }^{13-6} 91213$ Therefore, surgery alone cannot be the ideal solution to treat all skull base meningiomas, and less invasive therapeutic options have to be considered not only as adjunctive but as alternative primary treatment. ${ }^{2} 61014-20$

The promising results following gamma knife radiosurgery (GKRS) for skull base meningiomas in earlier reports ${ }^{17} 1820-25$ have to be interpreted with caution because most centres have related their early experience to short or mid term observation periods. The purpose of this clinical study was to analyse retrospectively the toxicity and effectiveness of radiosurgical treatment in our patients with basal meningiomas with a follow up of 5-12 years to allow comparison with the risk-benefit ratio of other therapeutic methods.

\section{PATIENTS AND METHODS}

From April 1992 to June 1999, 237 patients with benign skull base meningiomas were treated with GKRS at our department. Five patients died of causes unrelated to GKRS or basal meningioma before the observation time reached 5 years, and 32 patients were lost to follow up. The remaining 200 patients were included in this study. None had received external beam radiotherapy in the past. The median age of the 40 men and 160 women was 57 years (range 10-81). The locations of the skull base meningiomas are listed in table 1.

\begin{tabular}{|lc|}
\hline $\begin{array}{l}\text { Table } 1 \\
\text { patients with skull base meningiomas }\end{array}$ \\
\hline \multicolumn{2}{|c|}{$\begin{array}{l}\text { No. of } \\
\text { tumours }\end{array}$} \\
\hline Location & 69 \\
Cavernous sinus & 44 \\
Petroclival & 32 \\
Sphenoid wing & 21 \\
Cerebellopontine angle & 13 \\
Frontobasis & 10 \\
Orbita & 7 \\
Craniocervical & 4 \\
Sella & 200 \\
Total & \\
\hline
\end{tabular}

In total, 99 patients, who had undergone between one and four microsurgical resections, received additional GKRS 0.2195.1 months after their last craniotomy (median 3.1 months) to prevent a progressive growth of recurrent or residual basal meningiomas. All of these tumours were specified as grade 1 meningiomas according to the World Health Ornganization tumour classification. ${ }^{26}$ In total, 101 patients with typical findings on computerised tomography (CT) and/or magnetic resonance imaging (MRI) received GKRS as primary therapy because of medical infirmity, advanced age, or refusal of open surgery. None of the patients with primary GKRS suffered from increasing neurological deficit, especially progressive vision loss due to chiasmatic or optic nerve compression, as this is a clear indication for

Abbreviations: CND, cranial nerve deficit; $\mathrm{CT}$, computed tomography; GKRS, gamma knife radiosurgery; MRI, magnetic resonance imaging; PIV, prescription isodose volume 
Table 2 Distribution of pre- and postradiosurgical CNDs and neurological disorders in 200 patients with skull base meningiomas

\begin{tabular}{lcccl}
\hline & \multicolumn{5}{l}{ No. of patients } \\
\cline { 2 - 5 } Cranial nerve deficit & Before & After GKRS & \\
\cline { 2 - 5 } (CND)/clinical symptom & GKRS & Improved & Stable & Deteriorated \\
\hline Hyp/anosmia & 5 & - & 5 & - \\
Visual field defect & 63 & 18 & 43 & 2 (1 transient) \\
Oculomotor nerve palsy & 39 & 21 & 17 & 1 (transient) \\
Trochlear nerve palsy & 9 & 3 & 6 & - \\
Trigeminal sensory loss & 18 & 8 & 10 & - \\
Trigeminal neuralgia & 23 & 16 & 7 & $2^{*}$ (transient) \\
Abducent nerve palsy & 23 & 12 & 11 & - \\
Facial nerve palsy & 13 & 6 & 7 & - \\
Hearing loss & 20 & 1 & 19 & - \\
Tinnitus & 7 & - & 7 & - \\
Deglutition difficulty & 6 & - & 6 & - \\
Accessory nerve palsy & 3 & - & 3 & - \\
Tongue weakness & 4 & 1 & 3 & - \\
Hemiparesis & 11 & 5 & 6 & 2 \\
& & & & (1* unrelated, \\
Ataxia & 9 & 5 & 4 & - \\
Vertigo & 25 & 8 & 17 & - \\
Cephalea & 28 & 15 & 12 & 1 (transient) \\
Seizure activity & 7 & 2 & 4 & 1 (transient) \\
Exophthalmos & 15 & 8 & 7 & - \\
\hline *Appearance of new deficit following GKRS. & & \\
\hline
\end{tabular}

surgical resection of skull base meningiomas. The distribution of presenting clinical symptoms and signs at the time of GKRS is summarised in table 2 .

A Leksell gamma knife model B was used for radiosurgical treatment. Except for a 10 year old patient who was treated under general anaesthesia (fig 1), the fitting of the stereotactic frame was performed under local anaesthesia. Tumour localisation was based on high resolution contrast enhanced CT or gadolinium enhanced MRI. Before and after GKRS, calibre measurements were made in three separate dimensions and tumour progression or involution was defined as a change of $\pm 2 \mathrm{~mm}$. Volumetry was calculated at the time of GKRS but was not available for all cases in the follow up because several imaging studies were conducted by peripheral radiologists. Tumour volumes varied between 0.38 and $89.9 \mathrm{~cm}^{3}$ (median 6.5 ). Owing to large tumour volumes (19-89.8 $\mathrm{cm}^{3}$ ), we performed two stage radiosurgical treatment in seven patients and three stage GKRS in another to avoid adverse radiation related tissue effects.

Except for one patient who, for personal reasons, underwent the third radiosurgical partial volume treatment after 83.8 months, the intervals between gamma knife procedures ranged from 4.6 to 6.2 months (median 6). Treatment planning was performed using the Kula or GammaPlan software. Dose selection, guided by dose-volume analysis of prior radiosurgical series ${ }^{19}{ }^{27-29}$ and our previous experience, ${ }^{15171830-32}$ were tailored to each case on the basis of tumour volume, specific location, and the projected radiobiological risk of adjacent neural structures. Apart from three patients who were treated very early in this series with marginal doses of 7, 8, and 25 Gy respectively, doses of 10 $20 \mathrm{~Gy}$ (median 12) were delivered to the tumour borders, while the centres of the meningiomas received $15-56.7 \mathrm{~Gy}$ (median 26.7). Between 1 and 21 isocentres (median 6) were required to treat the mostly irregularly shaped meningiomas. The low doses were applied because of large tumour volume, and situation in the posterior fossa, to avoid radiation damage of the brain stem and cranial nerves. We retrospectively evaluated the conformity index according to the scoring ratio proposed by Paddick, ${ }^{33}$ which measures how well the created radiation field conforms to the size and shape of the target and attests that an undertreatment is as bad as an overtreatment. The theoretically perfect score of 1.00 lowers the smaller conformity the plan offers. Since October 2000, we have routinely applied the conformity index:

$$
\text { Conformity Index }=\frac{\mathrm{TV}_{\mathrm{PIV}}}{\mathrm{TV}} \times \frac{\mathrm{TV}_{\mathrm{PIV}}}{\mathrm{PIV}}=\frac{\mathrm{TV}_{\mathrm{PIV}}{ }^{2}}{\mathrm{TV} \times \mathrm{PIV}}
$$

where $\quad \mathrm{TV}=$ target volume, $\mathrm{PIV}=$ prescription isodose volume, and TVPIV = prescription target volume.

All patients were discharged within 24 hours following GKRS and were able to resume their preradiosurgical functional level within 3 to 5 days. Postradiosurgical imaging and clinical controls were conducted after 6 months, 12 months, and then once a year for the first 5 years, and if the tumour showed no growth, follow up was performed biennially thereafter. Tumour progression was defined as radiologically proven enlargement or need for additional surgical resection because of neurological deterioration despite an unchanged tumour volume. Rates of total tumour control were generated, and actuarial tumour control rates were calculated by the Kaplan-Meier method. ${ }^{34}$

\section{RESULTS}

\section{Radiological changes}

During the observation period of 5-12 years (median 7.9), the tumour volume remained stable in 83 patients $(41.5 \%)$ and decreased in $113(56.5 \%)$. Tumour enlargement was observed in four patients $(2 \%), 17,25,74$, and 77 months, respectively, after combined surgical and radiosurgical treatment. In 39 patients $(19.5 \%)$, reduced central contrast enhancement indicating marked tumour necrosis was demonstrated in the follow up studies. Temporarily increased peritumoural oedema, detected 3.6 and 6 months following secondary GKRS in two patients (1\%) with extensive meningiomas mostly located in the region of the cavernous sinus completely subsided after oral administration of dexamethasone.

\section{Clinical outcome}

The neurological examinations revealed stable clinical status in 108 patients $(54 \%)$ and improved neurological disorders in 83 cases $(41.5 \%)$. Of the patients with clinical amelioration, $21(10.5 \%)$ showed complete relief of neurological impairment, while transient (seven patients) or permanent (two cases) clinical deterioration was found in nine cases $(4.5 \%)$

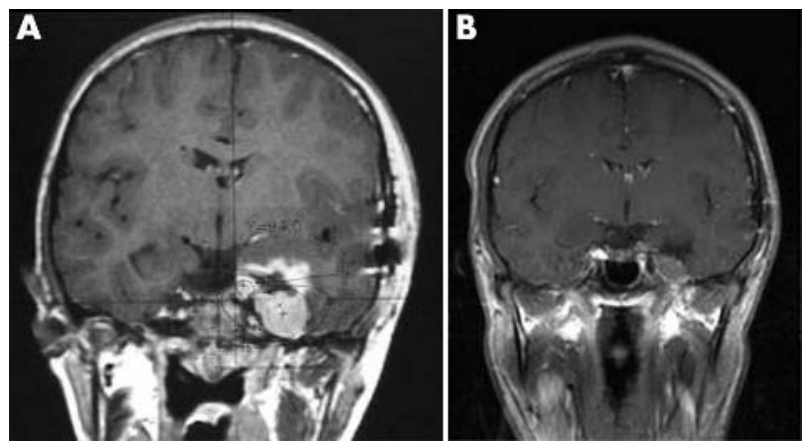

Figure 1 (A) T1 weighted, gadolinium enhanced, cranial MRI (coronal view) at the time of radiosurgery showing the size of residual left sided parasellar meningioma in a 10 year old patient 0.3 months after partial resection. The tumour volume of $3.9 \mathrm{~cm}^{3}$ received $20 \mathrm{~Gy}$ at the covering $40 \%$ isodose line. (B) Latest follow up scan conducted 128 months after GKRS demonstrating the reduced meningioma size. 
However, the permanent clinical worsening (new ipsilateral hemiparesis at 24 months following primary GKRS of a cavernous sinus meningioma) was not related to GKRS or tumour, but caused by stroke in a 68 year old patient. The distribution of preradiosurgical and postradiosurgical cranial nerve deficits and neurological disorders are listed in table 2.

\section{Salvage surgical procedures}

Five patients required repeated microsurgical resection after GKRS. In three patients, further debulking of the meningioma was necessary due to radiologically proven enlargement combined with neurological deterioration. Postoperatively, the impaired vision and oculomotor nerve dysfunction returned to normal in two patients respectively and the temporarily worsened hemiparesis in the third patient improved. Another patient with unaltered excellent clinical status underwent a second (conventional) surgery because the follow up scans displayed tumour progression. The remaining patient, harbouring a partially resected cavernous sinus meningioma with neuroradiologically unchanged extension, experienced progressive deterioration of a pre-existing visual field defect 5.5 months after radiosurgical treatment. The patient underwent microsurgical reoperation with further decompression of the optic chiasm and the optic nerve, but vision did not return to the same level as prior to GKRS.

\section{Complications following GKRS}

Five patients developed treatment related complications following GKRS, accounting for a complication rate of $2.5 \%$ ( $2 \%$ transient and $0.5 \%$ permanent complications). Increased seizure activity and aggravation of headache subsided completely in the two patients with temporarily increased peritumoural oedema. Two patients complained of new appearance of trigeminal neuralgia 12 and 16 months after secondary GKRS, respectively. No evidence of tumour progression was found on the imaging controls, and during the course of the following months, the trigeminal neuralgia resolved in both patients. The permanent visual deterioration in the patient with unchanged tumour volume that did not resolve after repeated microsurgery was considered as radiosurgically induced damage of the optic apparatus.

\section{Impact of conformity index on tumour control and complications}

We found 50 patients to have values below 0.7, 107 with scores between 0.7 and $0.9,35$ between 0.9 and 0.95 , and 9 $>0.95$. Of the four patients with tumour progression after GKRS, only one patient with a conformity index of 0.62 and treatment involvement of $85 \%$ of the meningioma had obviously received suboptimal treatment. In the remaining three patients, with scores of $0.83,0.85$, and 0.89 , progressive tumour growth was not caused by inadequate conformity.

The low index of 0.66 in our patient with permanent visual disturbance but radiologically stable tumour volume was caused by the attempt to shift the radiation dose away from the optic apparatus. The good conformity indices of 0.79 and 0.8 with the tumours totally covered by the prescription isodose volume do not explain the development of temporarily increased peritumoural oedema in two patients. The scores of 0.46 and 0.68 indicate undertreatment, but do not explain the occurrence of transient trigeminal neuralgia in two patients, as the radiosensitive structures of the cavernous sinus and the posterior fossa were deliberately excluded from radiosurgical treatment.

\section{Actuarial control rates}

Two patients with radiologically decreased tumour volume and improved neurological status died at 96 and 71 months

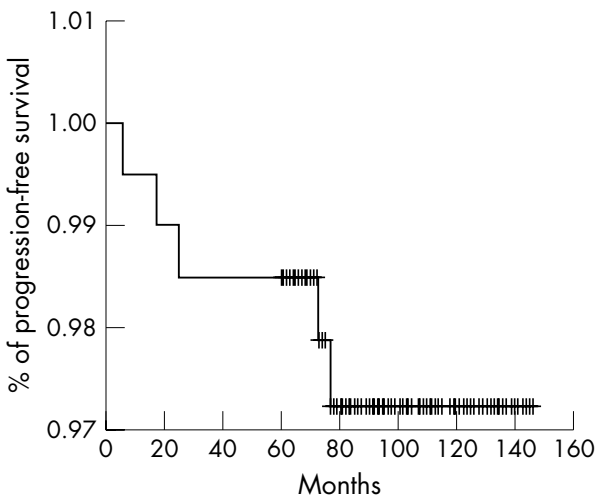

Figure 2 Kaplan-Meier ${ }^{34}$ curve showing progression free survival rates after gamma knife radiosurgery (GKRS) of benign skull base meningiomas in 200 patients.

following GKRS, due to unrelated intercurrent disease (lymphoblastic cancer and pneumonia), aged 72 and 82 years, respectively. Applying Kaplan-Meier method, ${ }^{34}$ progression free survival rate was $98.5 \%$ at 5 years' and $97.2 \%$ at 10 years' follow-up (fig 2).

\section{DISCUSSION}

The aim of microsurgery, which is considered the treatment of choice for skull base meningiomas, is complete excision with minimal morbidity and mortality. ${ }^{4}{ }^{4} 13193536$ In more recent series, total removal of basal meningiomas was achieved in $60-87.5 \%$ of the patients. Between $30 \%$ and $56 \%$ of the patients suffered postoperative complications, ${ }^{34937}$ but many authors mentioned only the percentage for specific complications and did not detail the absolute complication rate. ${ }^{25-810-12}$ The most common surgical sequelae were new or deteriorated pre-existing cranial nerve deficit (CND), occurring temporarily in $20-44 \%$ and permanently in $16-56 \%$ of the patients. The postoperative mortality rate ranges from $0 \%$ to $9 \%$ (median 3.6\%). ${ }^{1-12}{ }^{38}$ The variation of total recurrence rates among the surgical series (from $0 \%$ to $17 \%$, median $6.7 \%$ ) is seemingly caused by the range of the follow up periods. ${ }^{1-12}$ Furthermore, the recurrence/progression rates increase with the duration of follow up, and also seem to be influenced by tumour site and specific histopathological factors. ${ }^{36133539}$ Application of more sophisticated analysis, eventually including life table or KaplanMeier $^{34}$ studies, proved that the long term recurrence rates of microsurgically treated meningiomas are often underestimated. The risk of meningioma recurrence following total removal ranges from $3.5 \%$ to $19 \%$ at 5 years, whereas the 5 year progression rate of partially resected meningiomas varies between $25 \%$ and $60 \%{ }^{5}{ }^{13} 353839$ At 10 years, recurrence free rates range from $10 \%$ to $33 \%$ following radical resection, while tumour progression counts for $55-75 \%$ after partial meningioma removal. ${ }^{13} 3539$

As microsurgery alone still leaves us with a substantial recurrence or residual rate, considerable morbidity, and occasional mortality, less invasive alternative strategies have to be considered for the therapeutic management of basal meningiomas. ${ }^{2} 46101416-202429$ In elderly or medically infirm patients particularly, it must be considered whether the meningioma will be likely to cause serious problems in the natural course of the remaining years and if the risks of surgery will exceed the potential benefits offered.

Conventional radiation therapy for the management of recurrent, partially removed, or unresectable benign meningiomas seems to prevent or delay progressive tumour growth with local control rates of $76-92 \%$ at 5 years and $77-82 \%$ at 
Table 3 Summary of Linac based radiosurgical series for meningioma treatment

\begin{tabular}{|c|c|c|c|c|c|c|}
\hline Author & $\begin{array}{l}\text { No. of } \\
\text { patients }\end{array}$ & $\begin{array}{l}\text { Follow up, } \\
\text { range (median) }\end{array}$ & $\begin{array}{l}\text { Tumour volume }\left(\mathrm{cm}^{3}\right) \text {, } \\
\text { range (median) }\end{array}$ & $\begin{array}{l}\text { Marginal } \\
\text { dose (Gy), } \\
\text { range (median) }\end{array}$ & $\begin{array}{l}\text { Tumour } \\
\text { control } \\
\text { rate }(\%)\end{array}$ & $\begin{array}{l}\text { Comp } \\
(\%)\end{array}$ \\
\hline Engenhart $^{43}$ & 17 & 1 to $60(40)$ & $\mathrm{N} / \mathrm{A}$ & $\mathrm{N} / \mathrm{A}$ & 94 & 53 \\
\hline Chang $^{45}$ & 55 & 17 to $81(48.8)$ & 0.45 to 27.65 (7.33) & 12 to $25(18.3)$ & 98 & 24 \\
\hline Villavicencio ${ }^{44}$ & 56 & 6 to $66(26)$ & N/A & 12 to $18.5(15)$ & 95 & 9 \\
\hline
\end{tabular}

10 years. ${ }^{13} 36$ 40-42 Complications following irradiation developed in $3.6-19 \%$ of the cases. ${ }^{36}{ }^{40-42}$ One series reported that $9.4 \%$ of the patients with benign menigiomas died due to uncontrolled tumour growth following radiotherapy. ${ }^{42}$

Comparisons, especially with Linac accelerator based series, are of interest (table 3), but it is difficult to compare among series with missing variables (such as tumour volume and marginal dose). ${ }^{43}{ }^{44}$

Clinically, $64.7-91 \%$ of the patients remained unchanged or experienced improvement of neurological disorders. Permanent or transient CND were found in $3.6-22 \%$ of cases, parenchymal radiation necrosis developed in 3.6-11.8\%, and radiation induced oedema in 3.6-23.5\%. ${ }^{43-45}$ Engenhart et aI observed treatment related mortality in one patient $(5.9 \%)$ of their series. ${ }^{43}$

Within the past few years, GKRS has begun to play an increasingly important role as a non-invasive alternative therapeutic modality for patients with skull base meningiomas. ${ }^{17} 1820212425$ The aim of GKRS is to achieve long term tumour control with maintenance of the patient's clinical status and prevention of new treatment related morbidity. ${ }^{14} 162046$ Excellent results were related in the early to interim gamma knife series (table 4), but the follow up intervals of these reports are too short to ensure that the biological behaviour of basal meningiomas has been altered. ${ }^{14} 1718$ 20-25 Only very limited data concerning the long term effectiveness in the use of GKRS for meningiomas are available. ${ }^{15}{ }^{16}{ }^{47}$ In our current series with 5-12 years' follow up, local control of skull base meningiomas could be obtained in $97.5 \%$. The 5 year and 10 year progression free survival rates of $98.5 \%$ and $97.2 \%$, respectively, compare favourably with the results of other treatment methods. Most of the patients $(95.5 \%)$ had ameliorated or stable neurological status. Permanent clinical worsening was caused by unrelated intercurrent disease (stroke) in one patient. Transient deterioration in three patients with tumour progression was a result of tumour compression and cannot be considered a radiation induced complication. The permanently deteriorated vision in one patient, the temporary appearance of a trigeminal neuralgia in two patients, and the passing worsening in two patients with presence of transient radiation induced oedema were the only treatment related complications following GKRS, accounting for a complication rate of $2.5 \%$ ( $2 \%$ transient and $0.5 \%$ permanent complications). Similar results were reported by Kondziolka et al ${ }^{16}$ and Kobayashi et al..$^{47}$ In all of the series, no death resulted from the radiosurgical treatment of basal meningiomas with GKRS. Only one early report ${ }^{48}$ described neuroradiological changes in one of 50 patients $(2 \%)$ that could be attributed to radionecrosis of brain parenchyma.

Concerning the role of GKRS for primary treatment, an open microsurgical approach is recommended to establish tissue diagnosis if the findings on preradiosurgical MRI/CT scans do not clearly display the typical radiological features of benign meningioma, so that the possibility of other lesions can be ruled out. ${ }^{25}$

Comparison of the radiosurgical series of basal meningiomas shows a trend towards lower treatment doses over the years associated with unchanged excellent tumour control rates but reduced incidence of radiation induced adverse side effects. ${ }^{17} 1820-22243146485152$ Currently, we advocate that benign meningiomas should be treated with margin doses of $12 \mathrm{~Gy}$, but the radiosensitivity of juxtaposed cranial nerves or the brainstem sometimes necessitates an application of lower doses to the small portion of the meningioma borders directly in contact with the structures at risk. The anterior visual pathways seem to be less radio-resistant than the other cranial nerves. Although no clear threshold doses have been found for the optic nerve, chiasm, and $\operatorname{tract}^{30}{ }^{50}$ we keep maximum irradiation exposure of these structures below $10 \mathrm{~Gy}$. Nevertheless, one patient of our current series experienced permanent deterioration of vision without

\begin{tabular}{|c|c|c|c|c|c|c|}
\hline Author & $\begin{array}{l}\text { No. of } \\
\text { patients }\end{array}$ & $\begin{array}{l}\text { Follow up, } \\
\text { range (median) }\end{array}$ & $\begin{array}{l}\text { Tumour } \\
\text { volume }\left(\mathrm{cm}^{3}\right) \text {, } \\
\text { range (median) }\end{array}$ & $\begin{array}{l}\text { Marginal } \\
\text { dose (Gy), } \\
\text { range (median) }\end{array}$ & $\begin{array}{l}\text { Tumour } \\
\text { control } \\
\text { rate (\%) }\end{array}$ & $\begin{array}{l}\text { Comp } \\
(\%)\end{array}$ \\
\hline Kondziolka $^{29}$ & 50 & 6 to 34 (N/A) & N/A & 10 to $25(16.7)$ & 96 & 6 \\
\hline Duma $^{21}$ & 34 & 6 to 54 (26) & $\begin{array}{l}0.5 \text { to } 20.4 \\
(5.17)\end{array}$ & 10 to $20(16)$ & 100 & 20 \\
\hline Ganz $^{49}$ & 20 & 12 to 27 (N/A) & N/A & 5.1 to 28.5 (N/A) & 80 & 0 \\
\hline Nikolato $^{48}$ & 50 & 4 to 31 (14) & 0.6 to $20(8.6)$ & 10 to $28(18)$ & 98 & 6 \\
\hline Liscak $^{23}$ & 53 & 2 to 60 (19) & 0.9 to $31.4(7.8)$ & 10 to 14 (12) & 100 & 13 \\
\hline $\operatorname{lwai}^{22}$ & 24 & 6 to $36(17.1)$ & 0.1 to 28.6 (11) & 8 to $15(10.6)$ & 100 & 4 \\
\hline Morita $^{50}$ & 88 & 12 to $83(35)$ & N/A (10) & 12 to $20(16)$ & 98 & 14.8 \\
\hline Nakaya $^{46}$ & 11 & 21 to 57 (35.7) & 1.6 to $28.9(7.1)$ & 9.9 to $10(10)$ & 100 & 9 \\
\hline Kondziolka $^{16}$ & 99 & 60 to 120 (N/A) & 0.24 to $24(4.7)$ & 9 to $25(16)$ & 93 & 13 \\
\hline Aichholzer ${ }^{14}$ & 46 & 36 to $76(48)$ & N/A & 9 to 25 (15.9) & 97.5 & 4.3 \\
\hline Pend $^{32}$ & 164 & 25 to 97 (55) & 0.5 to $89.9(8.3)$ & 7 to 25 (12) & 98 & 1.8 \\
\hline Kobayashi: & 54 & 60 to $108(84)$ & N/A & N/A (14.5) & 89 & 5.5 (?) \\
\hline Eustacchio $^{15}$ & 121 & 60 to 117 (82) & 0.5 to $89.9(6.8)$ & 7 to 25 (13) & 98.3 & 3.3 \\
\hline Current study & 200 & 60 to 144 (95) & $\begin{array}{l}0.38 \text { to } 89.9 \\
(6.5)\end{array}$ & 7 to 25 (12) & 97.5 & 2.5 \\
\hline
\end{tabular}


tumour progression, although all parts of the optic pathways received less than $10 \mathrm{~Gy}$. The encouraging preliminary results after fractionated stereotactic radiotherapy for lesions directly abutting the critical structures of the optic apparatus, combining the advantages of physical dose localisation of stereotactic radiosurgery with the radiobiological benefits of dose fractionation, require studies with longer follow up periods to determine the value of this therapeutic approach. ${ }^{53}$ The nerves controlling the ocular muscles are presumed to tolerate doses even beyond $20 \mathrm{~Gy},{ }^{15} 19212930$ but in our patient, passing oculomotor nerve palsy developed, although no part of the third cranial nerve received more than 1020 Gy. Consistent with our experience, Morita et al found one patient to have permanent new oculomotor palsy following application of 10 Gy to the cavernous sinus. ${ }^{50}$

Prevailing reports stated that the fifth cranial nerve seems to tolerate doses of up to $20 \mathrm{~Gy},{ }^{15} 17193050$ but the new onset of transient trigeminal neuralgia following administration of 12-17 Gy to the trigeminal nerve was observed in two patients of our series.

Commonly, extensive intracranial lesions are considered not suitable for GKRS, because the radiobiological tolerance of the surrounding brain tissue for the currently prescribed single doses sets practical maximal volume limit to around $20 \mathrm{~cm}^{3} .{ }^{1628} 485154$ In fact, the passing peritumoural oedema, occurring in one patient very early in our study after a tumour volume of $23 \mathrm{~cm}^{3}$ had received an edge dose of $12 \mathrm{~Gy}$ at the $40 \%$ covering isodose line, seemingly resulted from inadequate dose-volume relation. Owing to this experience, we developed our proposed strategy of performing staged radiosurgical treatment for larger meningiomas to maximise potential benefits, which has been rarely described in adequate literature..$^{17} 222331$ As we obtained local tumour control and clinical amelioration in all cases following staged GKRS, we assume that this strategy may expand the indication for radiosurgical treatment in benign, slowly growing lesions with diameters larger than $3 \mathrm{~cm}^{.22}$ However, careful analysis of the treatment parameters (meningioma volume $7.4 \mathrm{~cm}^{3}$, margin dose $12 \mathrm{~Gy}$ at the $40 \%$ isodose curve) gave no explanation for the temporary appearance of radiation induced oedema in another patient.

The application of the aforementioned conformity index showed that tumour progression in one patient of our current series was due to undertreatment. Further data will be necessary to establish its final role in the treatment planning of GKRS.

Some authors have mentioned that surgical resection following GKRS becomes extremely difficult due to postirradiation changes in the tumour, such as formation of adherent scar tissue or loss of defining arachnoidal planes of dissection. ${ }^{55}{ }^{56}$ This is in contrast to our own experience in the two patients who underwent further, conventional surgery at our department after a combined surgical and radiosurgical treatment. During the operation, we found highly avascular tumour tissue, as we had expected, following endovascular occlusion of feeding vessels without any adherence to the juxtaposed neurovascular structures.

Aside from other considerations, appealing aspects of GKRS are the short duration of hospitalisation (less than 48 hours) and the quick return to normal daily life activities (3-5 days following GKRS) on the same level as prior to radiosurgery, thus favourably contributing to the cost effectiveness of this minimally invasive treatment method. ${ }^{21} 29$

\section{CONCLUSION}

In our 5-12 year experience, GKRS provided an excellent long term tumour control rate associated with maintenance of neurological function and low treatment related morbidity for selected patients with benign skull base meningiomas. The long term outcome following GKRS for skull base meningiomas treatment favourably compares with the results obtained by microsurgery, conventional radiotherapy, and Linac based radiosurgery either in combination or on its own. The apparently better results of GKRS in the treatment for skull base meningiomas should provide the impetus for even more aggressive application of this approach in the management of basal meningiomas.

Nevertheless, increasing neurological deficit, especially rapidly progressive vision loss due to chiasmatic or optic nerve compression, is a clear indication for surgical resection. With regard to the possibility of an additional radiosurgical approach to residual tumours and the excellent results, following combined microsurgical-radiosurgical treatment, the objective of surgical treatment of basal meningiomas should be preservation of function and of as much normal tissue as possible, rather than radical resection. Patients harbouring recurrences of skull base meningiomas should receive GKRS rather than undergo repeated open resection.

In patients with advanced age, significant concomitant medical problems, high risk tumour location or patients who are not willing to undergo an open microsurgical procedure, we would recommend performing GKRS as a safe and effective alternative primary treatment modality, with close and frequent clinical and neuroradiological follow up. However, the long natural history of skull base meningiomas necessitates observation periods of at least 10-20 years before any final conclusion regarding the various treatment options can be expected.

\section{Authors' affiliations}

W Kreil, J Luggin, I Fuchs, V Weigl, S Eustacchio, G Papaefthymiou, Department of Neurosurgery, Medical University, Graz, Austria

Competing interests: none declared

\section{REFERENCES}

1 Sekhar LN, Swamy NK, Jaiswal V, et al. Surgical excision of meningiomas involving the clivus: preoperative and intraoperative features as predictors of postoperative functional deterioration. J Neurosurg 1994;81:860-8.

2 Arnautovic KI, Al Mefty O, Husain M. Ventral foramen magnum meninigiomas. J Neurosurg 2000;92:71-80.

3 Bricolo AP, Turazzi S, Talacchi A, et al. Microsurgical removal of petroclival meningiomas: a report of 33 patients. Neurosurgery 1992;31:813-28.

4 Couldwell WT, Fukushima T, Giannotta SL, et al. Petroclival meningiomas: surgical experience in 109 cases. J Neurosurg 1996;84:20-8.

5 De Jesus O, Sekhar LN, Parikh HK, et al. Long-term follow-up of patients with meningiomas involving the cavernous sinus: recurrence, progression, and quality of life. Neurosurgery 1996;39:915-19.

6 DeMonte F, Smith HK, Al Mefty O. Outcome of aggressive removal of cavernous sinus meningiomas. J Neurosurg 1994;81:245-51.

7 George B, Lot G, Boissonnet H. Meningioma of the foramen magnum: a series of 40 cases. Surg Neurol 1997; 47:371-9.

8 Samii M, Tatagiba M. Experience with 36 surgical cases of petroclival meningiomas. Acta Neurochir (Wien) 1992; 1 18:27-32.

9 Samii M, Klekamp J, Carvalho G. Surgical results for meningiomas of the craniocervical junction. Neurosurgery 1996;39:1086-94.

10 Samii M, Carvalho GA, Tatagiba $M$, et al. Surgical management of meningiomas originating in Meckel's cave. Neurosurgery 1997;41:767-74.

11 Spallone A, Makhmudov UB, Mukhamedjanov DJ, et al. Petroclival meningioma. An attempt to define the role of skull base approaches in their surgical management. Surg Neurol 1999;51:412-19.

12 Thomas NW, King TT. Meningiomas of the cerebellopontine angle. A report of 41 cases. Br J Neurosurg 1996;10:59-68.

13 Mathiesen $T$, Lindquist $C$, Kihlstrom $L$, et al. Recurrence of cranial base meningiomas. Neurosurgery 1996;39:2-7.

14 Aichholzer M, Bertalanffy A, Dietrich W, et al. Gamma knife radiosurgery of skull base meningiomas. Acta Neurochir (Wien) 2000;142:647-52.

15 Eustacchio S, Trummer M, Fuchs I, et al. Preservation of cranial nerve function following Gamma Knife radiosurgery for benign skull base meningiomas: experience in 121 patients with follow-up of 5 to 9.8 years. Acta Neurochir Suppl 2002;84:71-6.

16 Kondziolka D, Levy El, Niranjan A, et al. Long-term outcomes after meningioma radiosurgery: physician and patient perspectives. J Neurosurg 1999;91:44-50.

17 Pendl G, Schrottner O, Eustacchio S, et al. Stereotactic radiosurgery of skull base meningiomas. Minim Invasive Neurosurg 1997;40:87-90. 
18 Pendl G, Schrottner O, Eustacchio S, et al. Cavernous sinus meningiomas what is the strategy: upfront or adjuvant gamma knife surgery? Stereotact Funct Neurosurg 1998;70(suppl 1):33-40.

19 Steiner L, Lindquist Ch, Steiner M. Meningiomas and Gamma Knife radiosurgery. Al Mefty, O. New York, Raven Press, 1991:263-72.

20 Subach BR, Lunsford LD, Kondziolka D, et al. Management of petroclival meningiomas by stereotactic radiosurgery. Neurosurgery 1998;42:437-43.

21 Duma CM, Lunsford LD, Kondziolka D, et al. Stereotactic radiosurgery of cavernous sinus meningiomas as an addition or alternative to microsurgery. Neurosurgery 1993:32:699-704.

22 Iwai Y, Yamanaka K, Yasui T, et al. Gamma knife surgery for skull base meningiomas. The effectiveness of low-dose treatment. Surg Neurol 1999;52:40-4.

23 Liscak R, Simonova G, Vymazal J, et al. Gamma knife radiosurgery of meningiomas in the cavernous sinus region. Acta Neurochir(Wien) 1999;141:473-80.

24 Muthukumar N, Kondziolka D, Lunsford LD, et al. Stereotactic radiosurgery for anterior foramen magnum meningiomas. Surg Neurol 1999;51:268-73.

25 Nakatomi H, Sasaki T, Kawamoto S, et al. Primary cavernous sinus malignant lymphoma treated by gamma knife radiosurgery: case report and review of the literature. Surg Neurol 1996;46:272-8.

26 Kleihues P, Burger PC, Scheithauer BW. The new WHO classification of brain tumours. Brain Pathol 1993:3:255-68.

27 Flickinger JC. An integrated logistic formula for prediction of complications from radiosurgery. Int J Radiat Oncol Biol Phys 1989;17:879-85.

28 Flickinger JC, Kondziolka D, Lunsford LD. Dose selection in stereotactic radiosurgery. Neurosurg Clin N Am 1999;10:271-80.

29 Kondziolka D, Lunsford LD, Coffey RJ, et al. Stereotactic radiosurgery of meningiomas. J Neurosurg 1991;74:552-9.

30 Leber KA, Bergloff J, Pendl G. Dose-response tolerance of the visual pathways and cranial nerves of the cavernous sinus to stereotactic radiosurgery. J Neurosurg 1998;88:43-50.

31 Pendl G, Unger F, Papaefthymiou G, et al. Staged radiosurgical treatment for large benign cerebral lesions. J Neurosurg 2000;93(suppl 3):107-12.

32 Pendl G, Eustacchio S, Unger F. Radiosurgery as alternative treatment for skull base meningiomas. J Clin Neurosci 2001;8(suppl 1):12-14.

33 Paddick I. A simple scoring ratio to index the conformity of radiosurgical treatment plans. Technical note. J Neurosurg 2000;93(suppl 3):219-22.

34 Kaplan E, Meier P. Nonparametric estimation from incomplete observations. $J$ Am Stat Assoc 1958;53:475-81.

35 Mirimanoff RO, Dosoretz DE, Linggood RM, et al. Meningioma: analysis of recurrence and progression following neurosurgical resection. J Neurosurg 1985:62:18-24.

36 Nutting C, Brada M, Brazil L, et al. Radiotherapy in the treatment of benign meningioma of the skull base. J Neurosurg 1999;90:823-7.

37 Cusimano MD, Sekhar LN, Sen CN, et al. The results of surgery for benign tumors of the cavernous sinus. Neurosurgery 1995;37:1-9.

38 Jung $\mathrm{HW}$, Yoo $\mathrm{H}$, Paek SH, et al. Long-term outcome and growth rate of subtotally resected petroclival meningiomas: experience with 38 cases. Neurosurgery 2000;46:567-74.
39 Ayerbe J, Lobato RD, de la CJ, et al. Risk factors predicting recurrence in patients operated on for intracranial meningioma. A multivariate analysis. Acta Neurochir (Wien) 1999;141:921-32.

40 Connell PP, Macdonald RL, Mansur DB, et al. Tumor size predicts control of benign meningiomas treated with radiotherapy. Neurosurgery 1999:44:1194-9.

41 Glaholm J, Bloom HJ, Crow JH. The role of radiotherapy in the management of intracranial meningiomas: the Royal Marsden Hospital experience with 186 patients. Int J Radiat Oncol Biol Phys 1990;18:755-61.

42 Goldsmith BJ, Wara WM, Wilson CB, et al. Postoperative irradiation for subtotally resected meningiomas. A retrospective analysis of 140 patients treated from 1967 to 1990. J Neurosurg 1994;80:195-201.

43 Engenhart R, Kimmig BN, Hover $\mathrm{KH}$, et al. Stereotactic single high dose radiation therapy of benign intracranial meningiomas. Int J Radiat Oncol Biol Phys 1990;19:1021-6.

44 Villavicencio AT, Black PM, Shrieve DC, et al. Linac radiosurgery for skull base meningiomas. Acta Neurochir(Wien) 2001;143:1141-52.

45 Chang SD, Adler JR Jr. Treatment of cranial base meningiomas with linear accelerator radiosurgery. Neurosurgery 1997;41:1019-25.

46 Nakaya K, Hayashi M, Nakamura S, et al. Low-dose radiosurgery for meningiomas. Stereotact Funct Neurosurg 1999;72(suppl 1):67-72.

47 Kobayashi T, Kida Y, Mori Y. Long-term results of stereotactic gamma radiosurgery of meningiomas. Surg Neurol 2001;55:325-31.

48 Nicolato A, Ferraresi P, Foroni R, et al. Gamma knife radiosurgery in skull base meningiomas. Preliminary experience with 50 cases. Stereotact Funct Neurosurg 1996:66(suppl 1):112-20.

49 Ganz JC, Backlund EO, Thorsen FA. The results of gamma nnife surgery of meningiomas, related to size of tumor and dose. Stereotact Funct Neurosurg 1993;61(suppl 1):23-9.

50 Morita A, Coffey RJ, Foote RL, et al. Risk of injury to cranial nerves after gamma knife radiosurgery for skull base meningiomas: experience in 88 patients. J Neurosurg 1999;90:42-9

51 Ganz JC, Schrottner O, Pendl G. Radiation-induced edema after gamma knife treatment for meningiomas. Stereotact Funct Neurosurg 1996;66(suppl 1):129-33.

52 Pan DH, Guo WY, Chang YC, et al. The effectiveness and factors related to treatment results of gamma knife radiosurgery for meningiomas. Stereotact Funct Neurosurg 1998;70(suppl 1):19-32.

53 Selch MT, Ahn E, Laskari A, et al. Stereotactic radiotherapy for treatment of cavernous sinus meningiomas. Int J Radiat Oncol Biol Phys 2004;59:101-11.

54 Kang CS, Zheng LG, Xu DS. Dose-volume effect in gamma knife radiosurgery of meningiomas. Stereotact Funct Neurosurg 1999:73:72-8.

55 Dolenc V. Comment to Liscak R, Simonova G, Vymazal J, Janouskova L and Vladyka V: Gamma knife radiosurgery of meningiomas in the cavernous sinus region. Acta Neurochir(Wien) 1999;141:480

56 Sekhar L. Comment to Iwai Y, Yamanaka K, Yasui T, Komiyama M, Nishikawa M, Nakajima H and Kishi H: Gamma knife surgery for skull base meningiomas. The effectiveness of low-dose treatment. Surg Neurol 1999;52:44. 